\title{
Gellan Gum Injectable Hydrogels for Cartilage Tissue Engineering Applications: In Vitro Studies and Preliminary In Vivo Evaluation
}

\author{
João T. Oliveira, Ph.D., ${ }^{1,2}$ Tírcia C. Santos, B.Sc., ${ }^{1,2}$ Luís Martins, B.Sc., ${ }^{3}$ Ricardo Picciochi, B.Sc., ${ }^{1,2}$ \\ Alexandra P. Marques, Ph.D.,, ${ }^{1,2}$ António G. Castro, Ph.D., ${ }^{3}$ Nuno M. Neves, Ph.D., ${ }^{1,2}$ \\ João F. Mano, Ph.D., ${ }^{1,2}$ and Rui L. Reis, Ph.D.,
}

Gellan gum is a polysaccharide that we have previously proposed for applications in the cartilage tissue engineering field. In this work, gellan gum hydrogels were tested for their ability to be used as injectable systems using simple processing methods, able to deliver and maintain chondrocytes by in situ gelation, and support cell viability and production of extracellular matrix (ECM). Rheological measurements determined that the sol-gel transition occurred near the body temperature at $39^{\circ} \mathrm{C}$, upon temperature decrease, in approximately $20 \mathrm{~s}$. Gellan gum discs shows a storage compression modulus of around $80 \mathrm{kPa}$ at a frequency of $1 \mathrm{~Hz}$ by dynamic mechanical analysis. Human articular chondrocytes were encapsulated in the gels, cultured in vitro for total periods of 56 days, and analyzed for cell viability and ECM production. Calcein AM staining showed that cell kept viable after 14 days and the histological analysis and real-time quantitative polymerase chain reaction revealed that hyaline-like cartilage ECM was synthesized. Finally, the in vivo performance of the gellan gum hydrogels, in terms of induced inflammatory reaction and integration into the host tissue, was evaluated by subcutaneous implantation in Balb/c mice for 21 days. Histological analysis showed a residual fibrotic capsule at the end of the experiments. Dynamic mechanical analysis revealed that the gels were stable throughout the experiments while evidencing a tendency for decreasing mechanical properties, which was consistent with weight measurements. Altogether, the results demonstrate the adequacy of gellan gum hydrogels processed by simple methods for noninvasive injectable applications toward the formation of a functional cartilage tissue-engineered construct and originally report the preliminary response of a living organism to the subcutaneous implantation of the gellan gum hydrogels. These are the two novel features of this work.

\section{Introduction}

C ARTILAge Is a tissue with relatively low or no turnover, both at cellular and molecular level, which leads to difficulties in its repair and regeneration once traumatized. The extracellular matrix (ECM) that is responsible for the functionality of the tissue has to be maintained by scarcely distributed chondrocytes, demanding a great anabolic capacity of these cells. Various therapeutic approaches that have no active biologics were involved, such as arthroscopy, debridement, laser abrasion, drilling, and microfracture. ${ }^{1-3}$ They involve mostly mechanical techniques that remove the affected tissue and seek to stimulate the formation of healthy tissue. Since the outcomes of these interventions are fre- quently not satisfactory, namely in terms of functional tissue recovery, alternative solutions for these problems are being explored. ${ }^{1,4,5}$ Brittberg et al. ${ }^{6}$ performed autologous chondrocyte transplantation in 1994 by injecting expanded chondrocytes into cartilage defects subsequently covered with a sutured periosteal flap. Although the results were successful in some cases, the percentage of failure led the researchers to pursue other lines of study, including the use of biomaterials and cells combined with bioactive agents in tissue engineering strategies. Several biomaterials, from either natural or synthetic origin, or combinations of both types, have been proposed as supports for cell development and tissue formation in cartilage tissue engineering. These include alginate, hyaluronic acid, collagen, fibrin, chitosan,

\footnotetext{
${ }^{1} 3 B^{\prime}$ s Research Group-Biomaterials, Biodegradables, and Biomimetics, Department of Polymer Engineering, Headquarters of the European Institute of Excellence on Tissue Engineering and Regenerative Medicine, University of Minho, Guimarães, Portugal.

${ }^{2}$ PT Associated Laboratory, IBB-Institute for Biotechnology and Bioengineering, Guimarães, Portugal.

${ }^{3}$ Life and Health Sciences Research Institute (ICVS), School of Health Sciences, University of Minho, Braga, Portugal.
} 
polyglycolic acid, or polyethylene oxide. ${ }^{7-10}$ Not only the type of material is important for the overall performance of the constructs but also its processing methodologies and the application routes employed. Hydrogels, and especially in situ injectable systems, have been gaining a wider interest for cartilage regeneration applications. ${ }^{11-15}$ They can be used in a minimally invasive manner by injecting into the defect area, normally involve nonharsh methods and reagents, possess the ability to adopt the shape of the defect thereby facilitating integration, and may be optimized for sol-gel transition to occur near body temperature while encapsulating cells and/or bioactive agents of interest.

Gellan gum is a new biomaterial recently proposed for tissue engineering applications, ${ }^{16}$ namely for cartilage regeneration. ${ }^{17,18}$ In addition to the above mentioned advantages of other injectable systems, gellan gum possess other features that may place it as a potential candidate for the clinical regeneration of cartilaginous tissues. Gellan gum is a linear anionic polysaccharide composed of repeating units of glucose, glucuronic acid, and rhamnose. ${ }^{19,20}$ It exists in the acetylated form, which is the initial raw material, and the deacetylated form, which is the most commonly used. ${ }^{21,22}$ Both form thermoreversible gels with differences in mechanical properties from soft and elastic for the acetylated form, to hard and brittle for the fully deacetylated polysaccharide which opens interesting prospects for the generation of multifunctional structures. ${ }^{22,23}$ Gellan gum is noncytotoxic and can be easily processed without the use of harsh reagents into transparent gels that are resistant to heat and acid stress. $^{24,25}$ Its gelation is ionotropic as in other polysaccharides, like alginate or carrageenan, and therefore the presence of cations is necessary for the formation of a stable hydrogel structure. Upon temperature decrease of a gellan gum solution, the transition of a thermally reversible coil to a doublehelix chain occurs and is followed by a self-assembling mechanism that forms oriented bundles. These link themselves through untwined polysaccharide chain regions culminating in the formation of a stable gel. ${ }^{26}$ The quantity and chemical nature of cations present in solution greatly affects gellan gum gelation; divalent cations promote a more efficient gelation than monovalent cations. ${ }^{26-28}$ Gellan gum gels are commonly used in the food industry as thickening agents or stabilizers. ${ }^{29}$ In the biomedical field, most applications are suggested for drug delivery approaches. ${ }^{30-32}$ Its use in cartilage tissue engineering was pioneered by our group, and the application for other soft tissues is currently under study.

In this work, gellan gum hydrogels were used as encapsulation agents and tissue engineering supports for human articular chondrocytes. Gellan gum properties were optimized and characterized so that they could be used as injectable systems in minimally invasive procedures using simple processing methodologies, being this one innovative feature of this work. Gellan gum with encapsulated human articular chondrocytes systems were tested in vitro for periods of up to 56 days of culture. Cell viability and ECM formation and deposition were evaluated by molecular and histological techniques. A preliminary in vivo evaluation of the gellan gum hydrogels was also performed upon subcutaneous implantation in Balb/c mice for total periods of up to 21 days. The obtained results showed the suitability of gellan gum hydrogels for injectable applications and in situ cell delivery, suggesting a potential application in the future toward the formation of functional tissue-engineered cartilage.

\section{Materials and Methods}

\section{Rheological studies}

Cone-plate rheometry was conducted for gellan gum hydrogels to assess their rheological behavior as function of temperature and time. For this purpose, gellan gum (G1910; Sigma-Aldrich, St. Louis, MO) powder was mixed at room temperature with distilled water at a concentration of $1 \%$ $(\mathrm{w} / \mathrm{v})$ under constant stirring. The solution was heated to $90^{\circ} \mathrm{C}$ and kept at this temperature for $30 \mathrm{~min}$. Afterward, $\mathrm{CaCl}_{2}$ was added to the gellan gum solution at a concentration of $0.03 \%(\mathrm{w} / \mathrm{v})$, and rheological measurements were performed using a controlled stress cone-plate rheometer (Reometer Reologica; StressTech, Lund, Sweden). For each measurement, a volume of $2 \mathrm{~mL}$ of the gellan gum solution was placed in the bottom plate of the rheometer and kept at a constant temperature of $70^{\circ} \mathrm{C}$. The polymer solution was allowed to stabilize for $1 \mathrm{~min}$ before starting the experiments. Measurements were performed by decreasing the temperature from $70^{\circ} \mathrm{C}$ to $25^{\circ} \mathrm{C}$ (at a cooling rate of $-6^{\circ} \mathrm{C} / \mathrm{min}$ ) and applying a constant shear stress of $0.1 \mathrm{~Pa}$. Temperature, time, shear rate, and viscosity were constantly measured. The total number of repeats was five $(n=5)$, and confidence intervals were estimated with a confidence level of $99 \%$.

\section{Dynamic mechanical analysis}

Dynamic mechanical analysis (DMA) was conducted to characterize the mechanical behavior of gellan gum hydrogel discs. The samples were prepared using a methodology previously described elsewhere. ${ }^{25}$ Gellan gum $1 \%(\mathrm{w} / \mathrm{v})$ discs ( $6 \pm 0.01 \times 5.5 \pm 0.46 \mathrm{~mm}$ height) were subjected to compression cycles of increasing frequencies ranging from 0.1 to $10 \mathrm{~Hz}$ with constant amplitude displacements of $0.1 \mathrm{~mm}$ using a Tritec 2000 DMA (Triton Technology, Nottinghamshire, United Kingdom). Storage and loss modulus were measured, and experiments were conducted at room temperature. The total number of discs per assay were five $(n=5)$. The described values for the compression modulus were collected at a frequency of $1 \mathrm{~Hz}$. Statistical analysis was performed using confidence intervals based on the experimental results, with a confidence level of $99 \%$.

\section{Human articular chondrocytes isolation and expansion}

Human articular cartilage was harvested from the femoral head and condyles of adult patients (40-65 years) undergoing knee arthroplasty surgery. This was performed within the scope of a protocol established with the Hospital de S. Marcos, Braga, Portugal, approved by its Ethical Committee and upon patient informed consent. Chondrocytes were isolated by enzymatic digestion; in detail, the human articular cartilage, free from all surrounding tissue, was placed in a Petri dish containing sterile phosphate-buffered saline (PBS) and cut into square slices of $5 \mathrm{~mm}$ and thickness between 2 and $3 \mathrm{~mm}$. The pieces were washed in sterile PBS, immersed in $20 \mathrm{~mL}$ of trypsin-ethylenediaminetetraacetic acid solution, and incubated for $30 \mathrm{~min}$ at $37^{\circ} \mathrm{C}$ under agitation. Trypsin was removed and the tissue pieces washed with basic Dulbecco's modified Eagle's medium (Sigma- 
Aldrich). Then $20 \mathrm{~mL}$ of sterile collagenase type II solution $(2 \mathrm{mg} / \mathrm{mL})$ (Sigma-Aldrich) in basic medium was added, and the mixture was incubated for approximately $12 \mathrm{~h}$ at $37^{\circ} \mathrm{C}$ under agitation. The digested tissue and cell suspension solution was centrifuged at $200 \mathrm{~g}$ for $7 \mathrm{~min}$ and the supernatant discarded. The cell pellet was washed with PBS and centrifuged again under the same conditions. Cells were again centrifuged, the supernatant removed, and resuspended in expansion medium consisting of Dulbecco's modified Eagle's medium (Sigma-Aldrich, MO, USA), containing $10 \mathrm{mM}$ [4-(2hydroxyethyl)-1-piperazineethanesulfonic acid] (HEPES) buffer $\mathrm{pH} 7.4,10,000$ units $/ \mathrm{mL}$ penicillin $/ 10,000 \mu \mathrm{g} / \mathrm{mL}$ streptomycin, $20 \mathrm{mM}$ L-alanyl glutamine, $1 \times$ minimum essential medium (MEM) nonessential amino acids, and $10 \%$ $(\mathrm{v} / \mathrm{v})$ fetal bovine serum (Biochrom, Berlin, Germany; heat inactivated), supplemented with $10 \mathrm{ng} / \mathrm{mL}$ basic fibroblast growth factor (PeproTech, London, United Kingdom). Human articular chondrocytes were plated onto tissue culture flasks and incubated at $37^{\circ} \mathrm{C}$ in a humidified atmosphere of $5 \% \mathrm{CO}_{2}$ in air for expansion. ${ }^{33}$

\section{Encapsulation of human articular chondrocytes in gellan gum hydrogels and in vitro culturing}

Human articular chondrocytes were expanded and encapsulated at passage 1 in gellan gum hydrogels using the following procedure. Gellan gum powder was mixed with sterile distilled water under constant stirring at room temperature to obtain a final concentration of $1 \%(\mathrm{w} / \mathrm{v})$. The solution was progressively heated to $90^{\circ} \mathrm{C}$ and kept at this temperature for 20-30 min. A sterile $\mathrm{CaCl}_{2}$ solution was added to obtain a final concentration of $0.03 \%(\mathrm{w} / \mathrm{v})$. The temperature was progressively decreased to $42^{\circ} \mathrm{C}$ and stabilized at this value for posterior use always under constant stirring. Human articular chondrocytes were detached by trypsinization, mixed with expansion medium, and centrifuged at $200 \mathrm{~g}$ for $7 \mathrm{~min}$. The supernatant was removed, and the cells were resuspended in warm sterile PBS solution, counted using an hemocytometer, and finally centrifuged at $200 \mathrm{~g}$ for $7 \mathrm{~min}$. The supernatant was discarded and the cells pellet kept at the bottom of the falcon tube. The gellan gum $1 \%(\mathrm{w} / \mathrm{v})$ with $\mathrm{CaCl}_{2} 0.03 \%(\mathrm{w} / \mathrm{v})$ solution was added to the pellet of cells and the mixture resuspended for complete homogenization of the cells within the matrix. Gellan gum discs containing $8 \times 10^{6}$ cells $/ \mathrm{mL}$ human articular chondrocytes were produced by casting this mixture into sterile cylindrical polystyrene moulds, allowing it to rest at room temperature for 1-2 $\mathrm{min}$ to form a solid gel. Discs of $\varnothing$ $6 \pm 0.01 \times 5.5 \pm 0.46 \mathrm{~mm}$ height were cut using a borer. The discs were cultured in the expansion medium for 7 days which was afterward replaced by differentiation medium for 49 days. The differentiation medium was prepared by replacing the basic fibroblast growth factor in the expansion medium with insulin $(1 \mu \mathrm{g} / \mathrm{mL})$ and ascorbic acid $(50 \mu \mathrm{g} / \mathrm{mL}$ ) (SigmaAldrich). The culture medium was changed every $3-4$ days.

\section{Cell viability: Calcein AM staining}

The viability of chondrocytes after 14 days of culture was assessed using calcein AM staining. Calcein AM (C3099; Invitrogen Corporation, Carlsbad, CA) assay is a fluorescence-based method for assessing cell viability and cytotoxicity in which the reagent is retained in cells that have an intact cell membrane. Briefly, a calcein AM solution of $1 / 1000$ was prepared in culture medium. After the end of each time point, one disc of gellan gum with encapsulated human articular chondrocytes was collected from the culturing plates and incubated in the calcein $\mathrm{AM}$ solution for $15-30 \mathrm{~min}$ at $37^{\circ} \mathrm{C}$ and afterward washed in sterile PBS. $4^{\prime}, 6-$ diamidino-2-phenylindole (DAPI) (Sigma-Aldrich, MO, USA), a fluorescent stain that binds strongly to DNA, was used for counterstaining. The samples were observed under fluorescent microscopy (Zeiss HAL 100/HBO 100; Axiocam MRc5, Oberkochen, Germany).

\section{Histology (hematoxylin-eosin, Alcian blue, Safranin-O)}

Histological analysis was performed with hematoxylineosin (H\&E), Alcian blue, and Safranin-O staining on $4 \mu \mathrm{m}$ thickness sections of the cell-scaffold constructs collected at different periods of culture. The samples were fixed in glutaraldehyde $2.5 \%(\mathrm{v} / \mathrm{v})$, for $30-40 \mathrm{~min}$ at $4^{\circ} \mathrm{C}$ and washed in PBS. Histological processing was performed using Tecnhovit $7100^{\circledR}$ (Heraeus Kulzer, Hanau, Germany) following the commercial procedure. Sections were cut using a microtome Leica RM2155 (Leica Microsystems, Nusslock, Germany). H\&E staining was performed using automatic processor (Leica Auto Stainer $\mathrm{XL}$ ) according to the in-house methodology (Leica TP1020-1; Leica MicroSystems). Histological staining with Alcian blue and Safranin-O was performed using standard histological methods. The slides were afterward washed three times in distilled water, quickly dehydrated through $95 \%$ and $100 \%$ ethanol, and then cleared in Histoclear ${ }^{\circledR}$ (National Diagnostics, Atlanta, GA) and mounted using Microscopy Entellan ${ }^{\circledR}$ (Merck, Rahway, NJ) for observation.

\section{Real-time polymerase chain reaction (Sox9, collagen type I, collagen type II, aggrecan)}

Samples were collected at defined time periods, quickly frozen in liquid nitrogen, and stored at $-80^{\circ} \mathrm{C}$ until the analysis was performed. RNA was extracted using TRIzol ${ }^{\circledR}$ (Invitrogen Corporation) according to the provided technical datasheet. Briefly, three samples of each condition were grinded and mechanically homogenized with a mortar and pestle in TRIzol reagent, each condition being performed in duplicate. Afterward, chloroform was added and the samples centrifuged to establish a three-phase composition in the tube. The aqueous phase was collected and put in a new tube where isopropanol was added. The samples were centrifuged, the supernatant discarded and the pellet washed with $75 \%$ ethanol. After a final centrifugation the samples were allowed to air dry, and suspended in ultrapure water for posterior analysis. The amount of isolated RNA and A260/280 ratio was determined using Nanodrop ND-1000 Spectrophotometer (NanoDrop Technologies, Wilmington, DE). After these determinations, $1 \mu \mathrm{g}$ of RNA of each sample was reverse transcribed into cDNA using the IScript ${ }^{\mathrm{TM}} \mathrm{CDNA}$ synthesis kit (Bio-Rad Laboratories, Hercules, CA) in a MJ Mini ${ }^{\mathrm{TM}}$ Personal Thermal Cycler (Bio-Rad Laboratories). Cartilage-related markers were chosen to evaluate the chondrogenic phenotype of the cultured systems. These included Sox9, collagen type I, collagen type II, and aggrecan, using GAPDH as the housekeeping gene for normalization. The expression of each gene was normalized to the GAPDH value in that sample. The 
Table 1. Primers Used for Real-Time Polymerase Chain Reaction Evaluation of Human Articular Chondrocytes Gene Expression

\begin{tabular}{lccc}
\hline Gene & Accession number & Left primer & Right primer \\
\hline Sox9 & NM_000346 & TTGAGCCTTAAAACGGTGCT & CTGGTGTTCTGAGAGGCACA \\
Collagen type I & NM_000089 & CTGCAAGAACAGCATTGCAT & GGCGTGATGGCTTATTTGTT \\
Collagen type II & NM_001844 & TCACGTACACTGCCCTGAAG & TGCAACGGATTGTGTTGTTT \\
Aggrecan & NM_001135 & ACAGCTGGGGACATTAGTGG & GTGGAATGCAGAGGTGGTTT \\
GAPDH & NM_002046 & GAGTCAACGGATTTGGTCGT & TTGATTTTGGAGGGATCTCG \\
\hline
\end{tabular}

relative gene expression quantification was performed using the $2^{-\Delta \Delta \mathrm{Ct}}$ (Livak) method, ${ }^{34}$ considering that

$$
2^{-\Delta \Delta \mathrm{Ct}}=\text { normalized expression ratio }
$$

All the primer sequences were generated using Primer3 ${ }^{\mathrm{TM}}$ software $^{35}$ and acquired from MWG Biotech ${ }^{\mathrm{TM}}$ (Ebersberg, Germany). More details can be found in Table 1. Real-time polymerase chain reaction (PCR) was performed using an MJ Mini Personal Thermal Cycler (Bio-Rad Laboratories, CA, USA) machine and SYBR Green IQ ${ }^{\mathrm{TM}}$ Supermix (Bio-Rad Laboratories, CA, USA) to detect amplification variations. The analysis of the results was performed with MJ Opticon Monitor 3.1 software (Bio-Rad Laboratories).

\section{Subcutaneous implantation in mice-histology and DMA}

Gellan gum discs were prepared under sterile conditions following a methodology previously described. ${ }^{25}$ Gellan gum $1 \%(\mathrm{w} / \mathrm{v})(\varnothing 6 \pm 0.01 \mathrm{~mm} \times 5.5 \pm 0.46 \mathrm{~mm}$ height $)$ discs were subcutaneously implanted in the dorsal part of the Balb/c mice (2-3 months with an average weight of $20 \mathrm{~g}$ ) during periods of up to 21 days. Six female mice were used (two for each period of implantation). Each animal was anaesthetized with a mixture of 5:1 Imalgene ${ }^{\circledR} 1000$ (Merial, Toulouse, France) and Domitor ${ }^{\circledR}$ (Orion Corporation, Espoo, Finland) ( $1.25 \mathrm{mg}$ per mouse and $25 \mu \mathrm{g}$ per mouse, respectively) prepared in physiological serum. Under surgical sterile conditions, two medial and ventral incisions (approximately $0.7 \mathrm{~cm}$ ) containing the subcutis and the panniculus carnosus (skin smooth muscle) were performed in the dorsum of the mice. Craniolateral oriented pockets (two per incision) were subcutaneously created by blunt dissection. Into these pockets, the gellan gum discs were inserted (four discs per animal), and the panniculus carnosus and the skin were carefully sutured. The animals were kept with food and water ad libitum during all the time of implantation. After predetermined time periods, each test animal was sacrificed, and the implanted scaffolds and respective surrounding tissue were explanted from each animal. These were subjected to macroscopic observation and processed for histological analysis to evaluate the induced inflammatory response and integration into the host tissue. Briefly, the explanted samples were fixed with formalin solution, dehydrated through ethanol solutions, and embedded in paraffin. Sections with $4 \mu \mathrm{m}$ thickness of the gellan gum structure and surrounding tissue interface were stained with H\&E using automatic coloring equipment, as previously described in the "Histology (hematoxylin-eosin, Alcian blue, Safranin-O Section)" section. DMA was also performed using the procedure previously described in the "Dynamic mechanical analysis" section.

\section{Results}

\section{Rheological studies}

Rheological measurements were performed mainly to determine the temperature range at which the sol-gel transition occurred and the time-scale for gelling as these are important parameters to look into when the material is expected to be applied as an injectable system and as a cell encapsulating agent. The sol-gel transition temperature was observed around $39^{\circ} \mathrm{C}\left(39.4 \pm 0.16^{\circ} \mathrm{C}\right)$ (Fig. 1). This enables the solution to be injected into the organism and gelate at the defect site once it stabilizes at the body temperature. Moreover, the low viscosity of the solution before gelation allows cells to be efficiently mixed and homogeneously dispersed within the carrier before the application. Regarding the time-scale for gelling, it is possible to observe from the graph in Figure 2 that it is approximately $20 \mathrm{~s}$. The results obtained for both temperature and time of gelation are critical to demonstrate the concept of using gellan gum hydrogels as injectable systems for minimally invasive surgical procedures in vivo. A gellan gum solution can be kept above the sol-gel transition maintaining a low viscosity that enables cells or bioactive agents of interest to be homogeneously dispersed. Upon lowering the temperature, the gel forms entrapping the cells in its matrix in a rather efficient way.

\section{$D M A$}

The viscoelastic characterization of the gellan gum hydrogels was performed using DMA. This technique also gives important information regarding the mechanical performance that these hydrogels may have once implanted

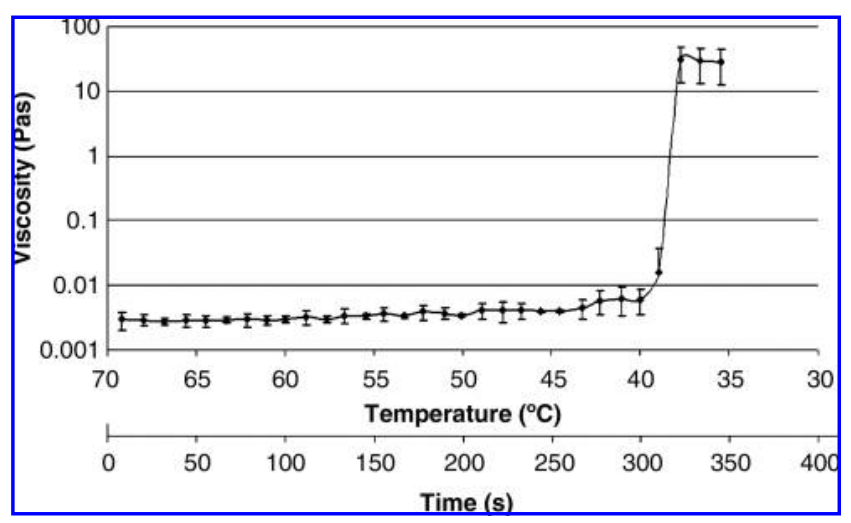

FIG. 1. Rheological measurements of gellan gum solutions showing the relation temperature-viscosity and timeviscosity. The sol-gel transition is noticeable by the change in viscosity present in the graph around $39^{\circ} \mathrm{C}$ with an extent of time for gelation of approximately $20 \mathrm{~s}$. 


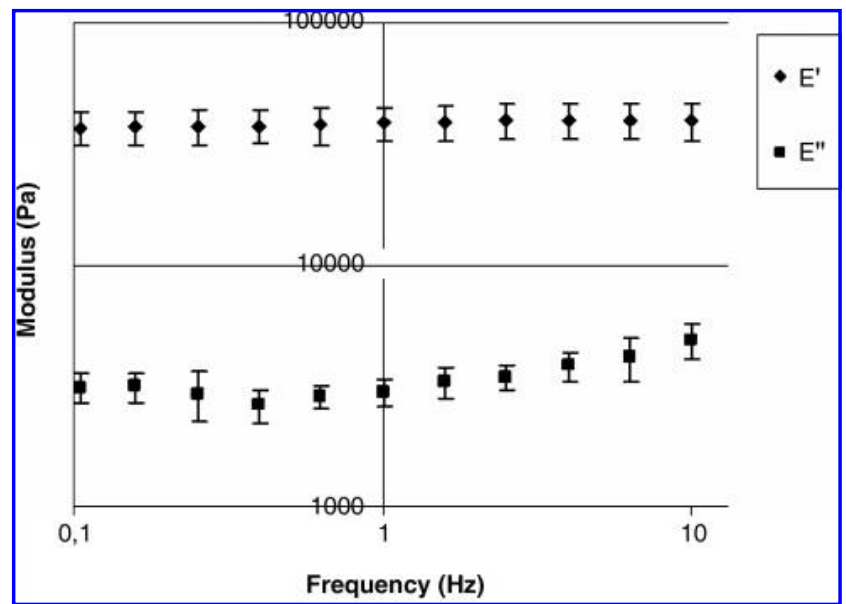

FIG. 2. Mechanical properties evaluation of gellan gum discs using dynamic mechanical analysis. The tests were performed in intervals of $0.1-15 \mathrm{~Hz}$ in hydrated samples.

in vivo. Gellan gum hydrogels were analyzed in the wet state throughout a physiological relevant frequency range. Storage (elastic) and loss (viscous) components of the complex modulus were determined and are shown in Figure 2. The storage modulus $\left(E^{\prime}\right)$ is about one order of magnitude higher than the loss modulus $\left(E^{\prime \prime}\right)$ which clearly reveals the elastic nature of these gels. It also possesses some damping capability that may be useful to dissipate cyclic mechanical energy that is imposed in an implantation scenario. Although some increase in $E^{\prime}$ is observed for increasing frequencies, the elastic properties of the hydrogel biomaterial, as compared with the viscous component, are quite stable. An increase in $E^{\prime \prime}$ is observed from 0.6 to $10 \mathrm{~Hz}$, suggesting a higher dissipation capability of gellan gum hydrogels at higher frequencies. At a frequency of $1 \mathrm{~Hz}$, the compression modulus of the gels was estimated to be of $78.6 \pm 2.3 \mathrm{kPa}$. In fact, although this value does not mimic the mechanical properties found in human articular cartilage, ${ }^{36}$ it is higher or within the range of values found for other hydrogels used in similar cartilage regenerative approaches. ${ }^{8,37}$

\section{Cell viability and histological analysis}

Calcein AM coupled with DAPI fluorescence staining was conducted to confirm the chondrocyte viability. Calcein AM penetrates the cell membrane of living cells, being subsequently hydrolyzed to a cell membrane-impermeable green fluorescent calcein by esterases present in viable cells. DAPI is a fluorescent stain that binds strongly to DNA. By coupling these two agents, viable cells are presented with green cytoplasm and blue nuclei. Results from samples collected after 14 days of culture are presented on Figure 3 showing viable human chondrocytes inside the hydrogels. The majority of the cells were positive for calcein and DAPI, which indicates a dominance of viable cells. These results show that both the gellan gum hydrogel is not cytotoxic and that the temperature cycle used to promote the sol-gel transition does not affect the cell viability.

Histological analysis of samples taken after 56 days of culture was performed using H\&E for regular morphological

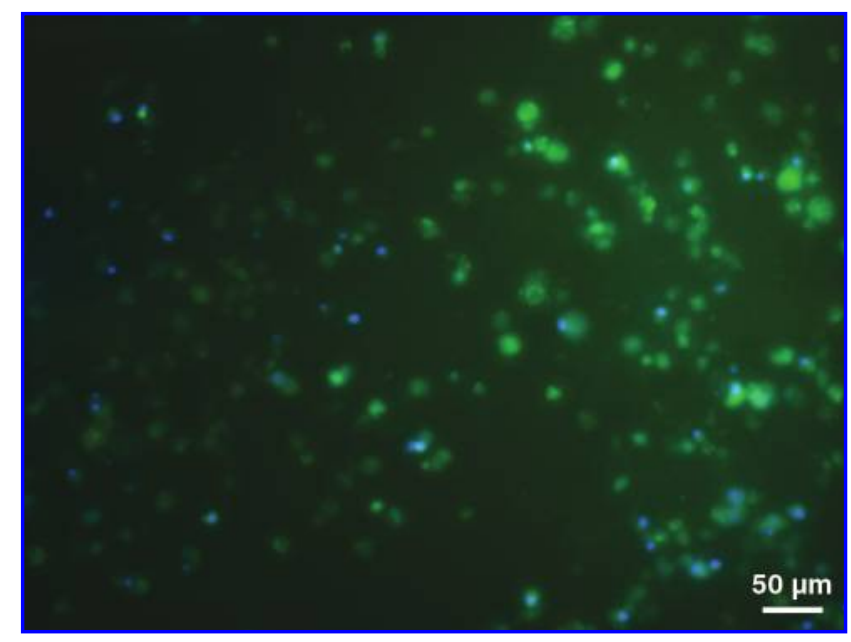

FIG. 3. Calcein AM/4',6-diamidino-2-phenylindole viability staining of human articular chondrocytes encapsulated in gellan gum hydrogels at 14 days of culture. Color images available online at www.liebertonline.com/ten.

cellular analysis, Alcian blue, and Safranin-O that are commonly used for staining ECM proteoglycans (glycosaminoglycans). H\&E-stained slides (Fig. 4A, B) show an homogeneous chondrocyte distribution throughout the gellan gum hydrogel matrix. Representative images of the deposition of proteoglycans (glycosaminoglycans) within the gellan gum matrix, commonly found in native articular cartilage ECM, can be found in Figure 4C and D. A positive staining in some pericellular areas of newly formed cell clusters was observed. An improvement in the nature of the staining that evolved from a more orthochromatic in the initial periods of culture (data not shown) to a more pronounced metachromatic staining in the latter periods was also noticed. This effect was more evident in the regions where cell clusters formed in comparison to individual chondrocytes.

\section{Real-time PCR (Sox9, collagen type I, collagen type II, aggrecan)}

Real-time PCR is frequently used to amplify and simultaneously quantify a specific sequence in a DNA sample. This technique was used to assess the expression profile of different molecules associated with hyaline cartilage ECM and thereby evaluate the nature and type of matrix that is being formed. Quantitative data may be obtained on gene expression and variations that are occurring (upregulation or downregulation) in comparison to a housekeeping gene. Sox9, collagens type I and II, and aggrecan are common ECM constituents, and their expression pattern from 14 to 56 days of culture was assessed (Fig. 5). GAPDH was chosen as the reference housekeeping gene since most of the studies presented on chondrocytes gene expression use this standard and therefore the results can be analyzed in a comparative way. The cycle threshold $(\mathrm{Ct})$ value for each sample was determined only when the exponential phase of amplification was reached. In each sample, the $\mathrm{Ct}$ value was normalized to the $\mathrm{Ct}$ value of the reference gene (GAPDH). Collagen type II and aggrecan are considered to be the two 


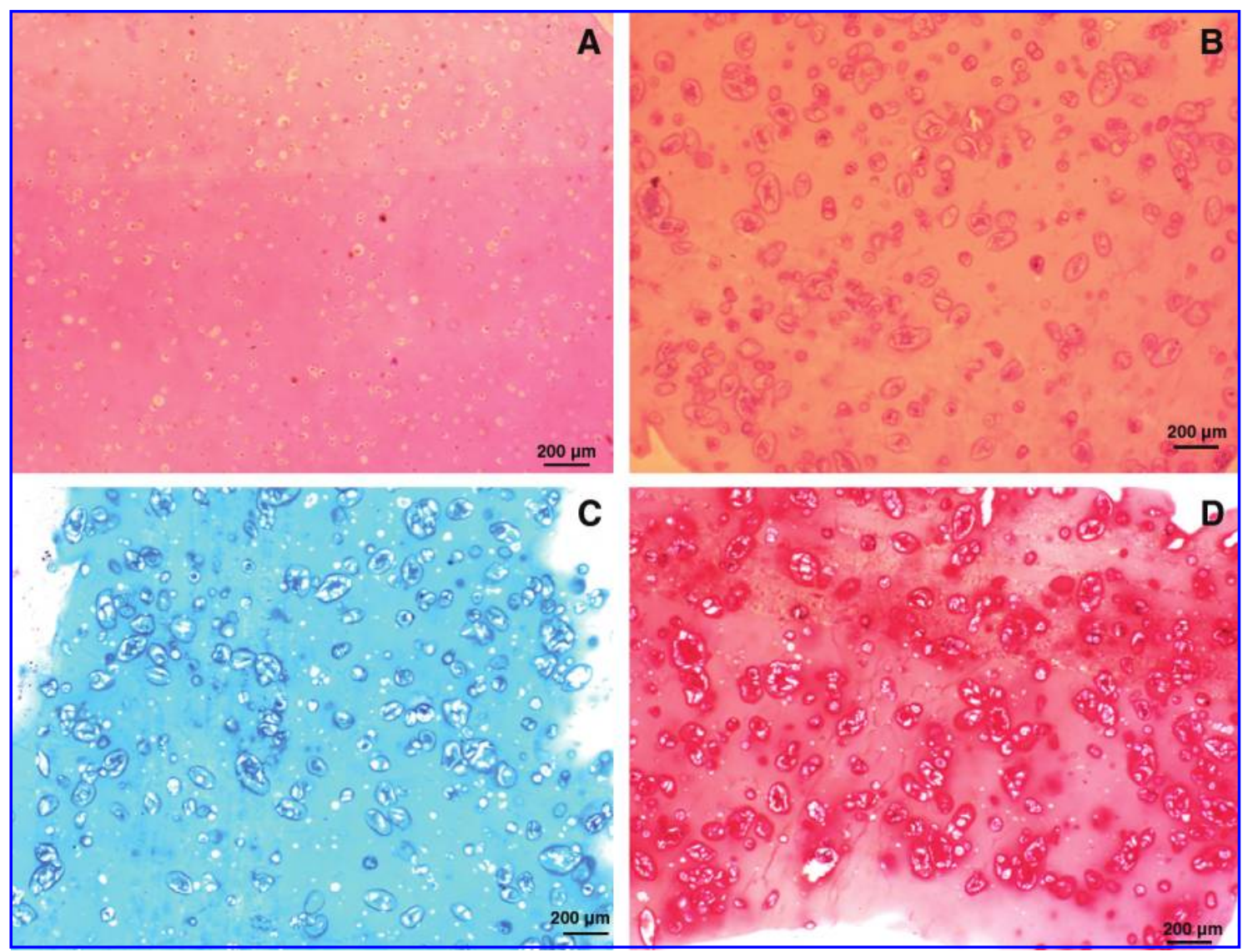

FIG. 4. Histological analysis of sections of gellan gum with human articular chondrocytes after culturing. Hematoxylineosin (A, B-after 2 and 56 days of culture, respectively) was used for general cell morphology and distribution, whereas Alcian blue (C) and Safranin-O (D) were performed for proteoglycans (glycosaminoglycans) detection. Color images available online at www.liebertonline.com/ten.

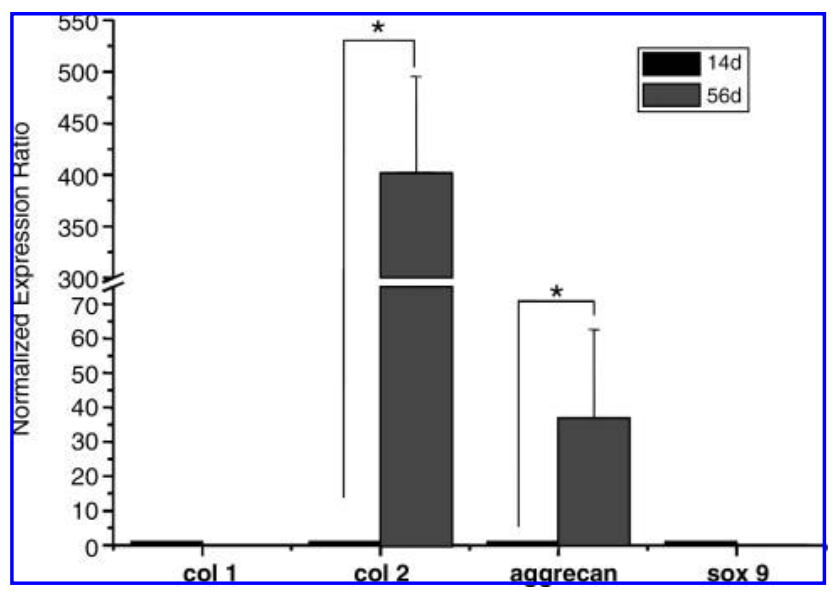

FIG. 5. Graphical representation of the real-time semiquantitative polymerase chain reaction analysis for collagen type I, collagen type II, aggrecan, and Sox9 based on the mRNA produced by the encapsulated human articular chondrocytes after 14 and 56 days of culture. Statistical analysis through the various time points $(p>0.05)$ was performed using a two-sample $t$-test assuming unequal variances for $n=3, \alpha=0.05$. Statistically significant differences are marked with an asterisk $\left(^{*}\right)$. major and most important constituents of hyaline cartilage ECM since the functionality of this tissue relies mostly on the presence of these components. Both collagen type II and aggrecan experienced a significant increase of approximately 400 -fold and 35-fold, respectively, from 14 to 56 days of culture in the gellan gum with encapsulated human chondrocytes hybrid systems. Collagen type I was not detected after 56 days and Sox 9 was downregulated to values close to zero from 14 to 56 days.

\section{In vivo tests: Histology, mechanical analysis, and weight measurements}

The initial response of a living organism to any kind of implanted biomaterial is absolutely necessary before proceeding to further tissue engineering studies. For this, the subcutaneous implantation of a biomaterial and the subsequent evaluation of the extent of the provoked inflammatory response is a common first screening methodology. As a way to confirm the adequacy of the developed hydrogels to be put through further screening, gellan gum discs were subcutaneously implanted in the back of Balb/c mice for periods of up to 21 days. Upon explantation, no evident macroscopic changes of the discs and surrounding tissues were observed after this period and the discs maintained its structural 


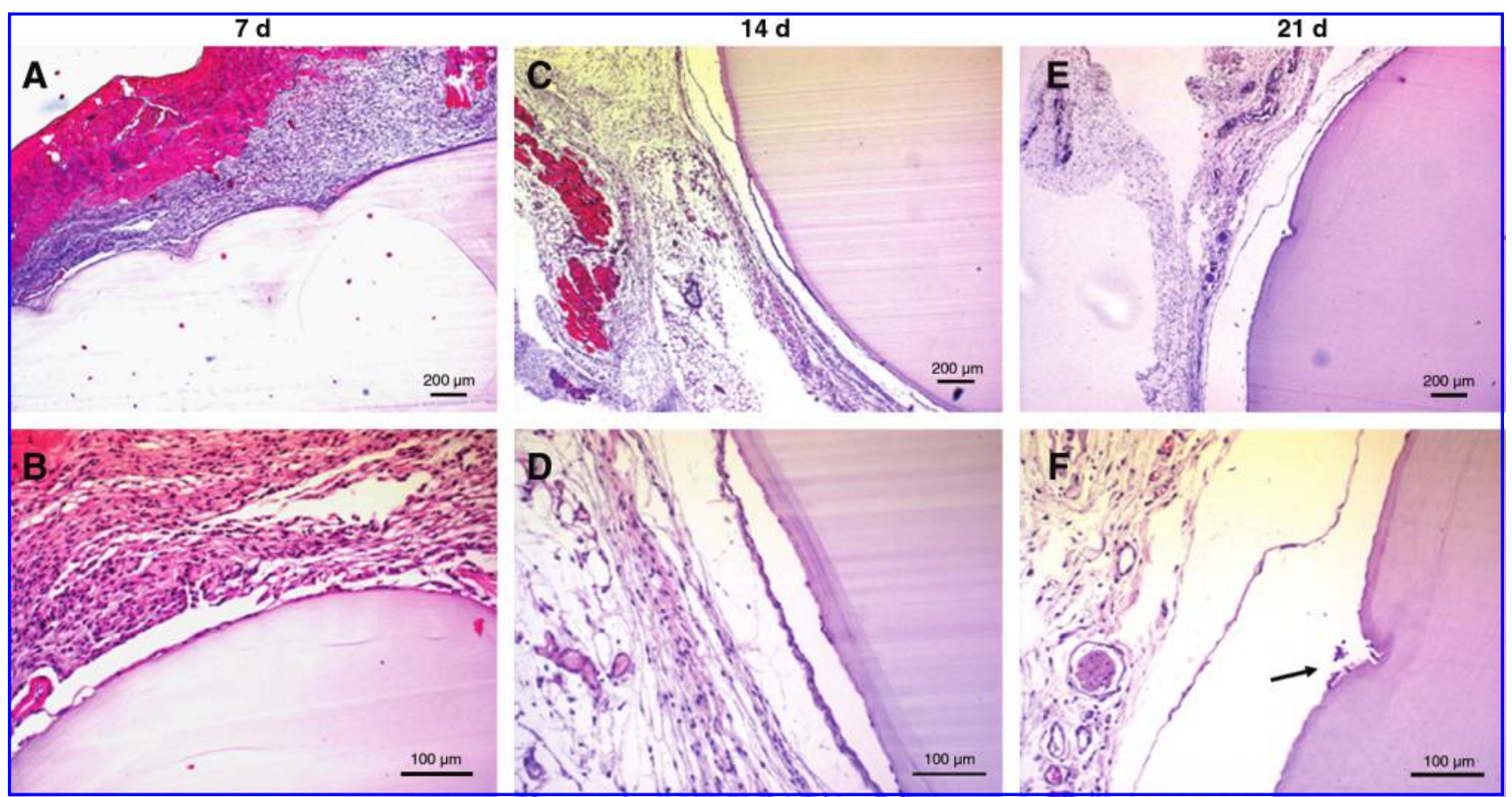

FIG. 6. Histological analysis showing two different magnifications of sections of gellan gum after 7 (A, B), 14 (C, D), and $21(\mathrm{E}, \mathrm{F})$ days of implantation. The images evidenced a good integration with the surrounding tissue and the progressive reduction of the fibrotic capsule that was almost unnoticed after 21 days. The arrow $(\mathbf{F})$ indicates the infiltration of phagocytic cells. Color images available online at www.liebertonline.com/ten.

integrity. Histological analysis of the explanted samples, stained with H\&E, showed good integration within the surrounding host tissue. In terms of inflammatory responseassociated cells, the normal presence of neutrophils was observed at 7 days of implantation (Fig. 6A, B). This cell population revealed a progressive decrease along the implantation time, almost inexistent at 14 days (Fig. 6C, D). Additionally, a thin and residual fibrotic capsule (Fig. 6E, F) and the infiltration of some phagocytic cells (Fig. 6F, arrow) were evident by the end of 21 days. DMA performed on the hydrogel samples at different periods of explantation re-

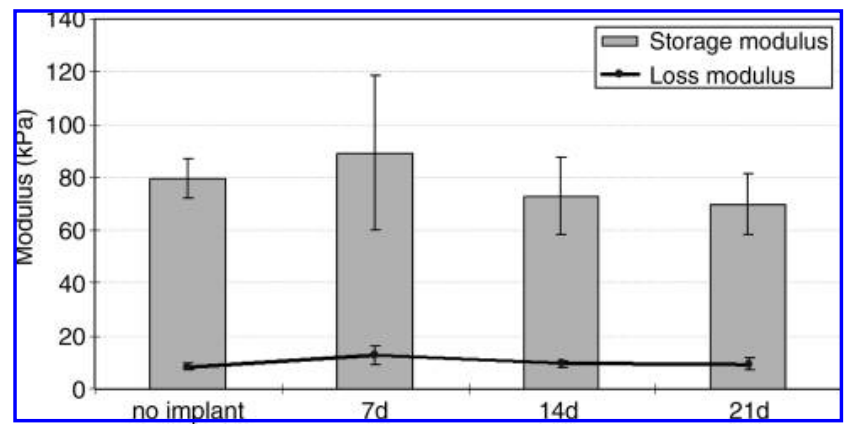

FIG. 7. Storage and loss modulus at $1 \mathrm{~Hz}$ obtained from compression dynamic mechanical tests of gellan gum discs after subcutaneous implantation in Balb/c mice. Statistical analysis was performed using a two-sample $t$-test assuming unequal variances for $n=5, \alpha=0.05$ and revealed no difference through the various time points $(p>0.05)$. vealed no statistically significant differences between the samples, although a slight decrease tendency in the compressive modulus was noticed (Fig. 7). In terms of weight measurements, which can be an indicator of biodegradation of gellan gum hydrogels, a statistical difference was observed after 21 days of implantation. Although the weights of the samples at different time points did not present relevant alterations, a statistically significant decrease was noticed after 21 days when compared with nonimplanted gellan gum gel discs and gel discs with 14 days of implantation (Fig. 8).

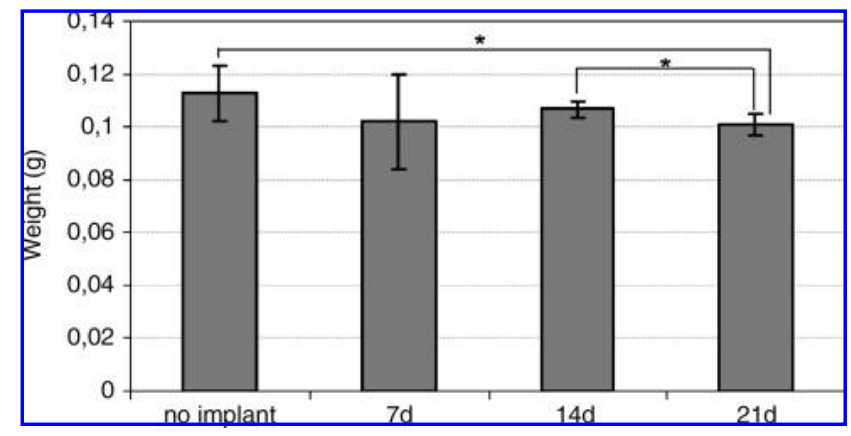

FIG. 8. Weight measurements of gellan gum discs after subcutaneous implantation in Balb/c mice. Statistical analysis revealed a significant difference $\left({ }^{*}\right)$ in gellan discs implanted for 21 days when compared with no implant and 14 days of implantation. Statistical analysis through the various time points $(p>0.05)$ was performed using a two-sample $t$-test assuming unequal variances for $n=5, \alpha=0.05$. 


\section{Discussion}

The use of hydrogels in cartilage regeneration is considered to be a promising strategy due to some intrinsic features that they frequently exhibit. Most of them can be applied as minimally invasive systems that are able to deliver cells and/or bioactive agents of interest in situ and to keep them at the implantation site. The processing under mild conditions coupled to the use of nonharsh reagents is another positive aspect. In addition, the gelation in situ enables the formed hydrogel to quickly set its volume and easily adapt to the shape of the defect site, establishing an efficient integration with the host tissue. ${ }^{38}$ Gellan gum is a new biomaterial proposed for cartilage regeneration that exhibits those features. It can be prepared by simple methods using nonaggressive reagents and can be combined with cells or bioactive agents of interest at the body temperature and physiological $\mathrm{pH}$. It can be injected under a minimally invasive surgical intervention and gelate upon temperature stabilization at body temperature giving rise to an efficient defect filling and cell entrapment system. Another potentially interesting aspect is the structural unit of gellan gum that includes glucuronic acid in its composition. ${ }^{19}$ This monosaccharide residue possesses a functional carboxylic group that may be modified to confer improved functionalities to this biomaterial. One final aspect is the fact that this biomaterial is already used in humans in ophthalmic applications, ${ }^{39}$ which may clearly enable a fast approval by the regulatory bodies. In this work, gellan gum hydrogels were tested for their ability to be used as injectable systems using simple methods in cartilage repair applications, which may be useful in the future in minimally invasive approaches. The injectability of this biomaterial was analyzed and confirmed by rheological measurements. Cone-plate rheology was used to determine the temperature range and time duration of the sol-gel transition in gellan gum hydrogels. The gellan gum solution revealed a consistent increase in viscosity around $40^{\circ} \mathrm{C}$ that stabilized at approximately $39^{\circ} \mathrm{C}$, being the temperature at which the gelation process is finalized. This analysis also provided data on the time during which this process occurred which was shown to be of approximately $20 \mathrm{~s}$. The interpretation of both these parameters demonstrates the potential of these hydrogels to be used as minimally invasive injectable systems that are able to deliver and encapsulate cells and/or bioactive agents to a defect site in the human body. In addition, the injectability of gellan gum hydrogels is good since their viscosity before the onset of gelation is low, enabling the overall mixing and application of the gel to be easily conducted. Mechanical properties tested using DMA retrieved a wet state compression modulus of approximately $80 \mathrm{kPa}$ at a frequency of $1 \mathrm{~Hz}$ analyzed in the wet state using a physiologically relevant frequency range. The storage modulus $\left(E^{\prime}\right)$ is about one order of magnitude higher than the loss modulus $\left(E^{\prime \prime}\right)$ which indicates an elastic nature of gellan gum. Some damping capability was noticed when analyzing $\tan \delta$ results, which may be considered an advantage for dissipating some cyclic mechanical energy that is generated in vivo. This value is fairly good when compared to other hydrogels frequently described in the literature for cartilage regenerative approaches. ${ }^{8,37}$ Nonetheless, human cartilage exhibits higher compressive modulus of approximately one order of magnitude. ${ }^{36}$ This difference is expected to be compensated by ECM deposition during the formation of a cartilaginous structure. ${ }^{8}$ In vitro tests showed that chondrocytes were viable and homogeneously distributed inside the hydrogels as observed under fluorescence microscopy using calcein AM combined with DAPI and H\&E staining. The chondrocytes' typical roundshaped morphology was confirmed at both initial and longterm culture periods. Cell dispersion throughout the gellan gum matrix was quite homogeneous and the cells maintained normal morphological features and active division to some extent. Using the calcein AM-DAPI staining it was possible to observe that the chondrocytes are viable inside the matrix, although cell division state may somehow be limited due to the physical restrictions of the hydrogel network which is a typical feature in similar systems. ${ }^{40}$ Nonetheless, it may be that the carbohydrate nature of gellan gum, which contains high glucose content, can be used as a source of energy by the cells, thereby progressively giving rise to spaces within the hydrogel matrix and the consequent chondrocyte proliferation. Ongoing work performed by our group on the subcutaneous implantation of gellan gum discs through extensive periods has gathered consistent information that corroborates this hypothesis. Other mechanical events associated with cell proliferation may include the formation of microcracks and the propagation of fracture creating additional spaces for cell growth. Besides cells' viability and distribution, the formation of an adequate ECM is of utmost importance to the performance of the tissueengineered construct. Active collagen type II and aggrecan deposition contributes to the formation of a functional hyaline-like cartilage-engineered tissue. These are in fact the two major ECM molecules responsible for the articular cartilage mechanical properties; collagen type II confers tensile strength, and aggrecan is responsible for the compressive resistance. ${ }^{41}$ Alcian blue and Safranin-O performed after 56 days of culturing on sections of gellan gum with encapsulated human articular chondrocytes evidenced glycosaminoglycans deposition in the pericellular regions of most cell clusters. Real-time PCR analysis for Sox9, collagen I, collagen II, and aggrecan strengthened these findings confirming the increased levels of expression of transcripts from collagen type II and aggrecan from 14 to 56 days. Collagen type II was upregulated approximately 400-fold and aggrecan approximately 35-fold; no statistically significant variation in Sox9 was encountered and no collagen type I was detected. Such results clearly show that human articular chondrocytes encapsulated in gellan gum hydrogels were able to deposit a hyaline-like ECM, therefore contributing to the formation of a functional tissue-engineered construct. However, the low expression of Sox9 seems to diverge from this pattern since this factor is apparently associated with the chondrocyte phenotype maintenance and collagen type II expression, although this is not consensual. ${ }^{42,43}$ Chondrocytes from osteoarthritis cartilage present low levels of Sox $9,{ }^{43}$ and the cell source may be a possible explanation for this occurrence. Also, the dedifferentiation process occurring during in vitro expansion ${ }^{44}$ or the existence of some associated hypertrophy of the chondrocytic cells may be occurring. ${ }^{45}$

The following step in this study was to evaluate the response of a host to a first contact with this biomaterial, which 
to our knowledge is for the first time report in this work. Gellan gum discs were subcutaneously implanted in the back of Balb/c mice, and histological analysis was conducted to assess the inflammatory processes associated with the implantation, as well as the integration into the host tissue. A negligent, thin, and residual fibrotic capsule was observed with no evident polymorphonuclear and mononuclear cells present, as well as a good integration with the involving tissues. It should be mentioned that some phagocytic cell infiltration (Fig. 6F, arrow) into the hydrogel matrix was observed after 21 days, indicating that this might be a probable scenario in further in vivo studies. One might speculate that such an event will enable gellan gum with encapsulated cell systems to efficiently integrate with the host tissues and establish a functional transition zone at the interface area, although this must be shown in further studies.

DMA performed on the explants after the defined time periods revealed no statistically significant differences among the various samples. Weight measurements showed that although no relevant alterations were detected, a significant decrease was noticed after 21 days. This may correlate with some cell infiltration into the gellan gum hydrogel matrix and possible resorption, as observed in the histological analysis. In an in vivo scenario where the gellan gum carries encapsulated cells intended to form a tissue, the tendency may be the deposition of a cartilage-like ECM along with the possible degradation of the hydrogel. Further studies on this respect will be conducted to understand how gellan gum will degrade or will be replaced at the implantation site by the newly formed tissue. As a summary, this work demonstrates the potential of gellan gum hydrogels to be used as injectable systems in minimally invasive surgical procedures for cartilage regeneration. The properties of this biomaterial were characterized and shown to be compatible with the application envisaged. The in vitro studies with clinically relevant cells showed successful human articular chondrocyte viability and ECM formation, culminating with the in vivo reaction evaluation upon implantation of the gels in an ectopic site. The overall data analysis shows that this injectable system has all the requirements to be used for cartilage tissue engineering and its potential should continue to be assessed by further in vivo studies.

\section{Conclusions}

Gellan gum hydrogels were originally proposed and used in the herein presented studies as injectable systems for cell delivery and support, aimed at cartilage regeneration, using simple nonharsh processing methodologies. Gellan gum ability to be applied as a minimally invasive system upon injection and in situ gelation was supported by rheological measurements. The gels exhibit a low viscosity between $42^{\circ}-$ $41^{\circ} \mathrm{C}$ enabling an efficient and homogeneous mixing of the cells, that can afterwards be injected forming a stable gel with entrapped cells when reaching the body temperature. Gelation occurs around $39^{\circ} \mathrm{C}$ in about $20 \mathrm{~s}$. The evaluation of the mechanical properties of the hydrogels showed that these are within the normal range of other hydrogels used in these applications and should be able to adapt to the cartilage en- vironment. In vitro tests performed with human articular chondrocytes encapsulated in gellan gum hydrogels revealed that the cells remained viable and produced hyaline-like ECM as observed by the significant increase of collagen type II and aggrecan after 56 days of culture. Subcutaneous implantation of these materials in the back of mice revealed highly satisfactory results since the histology evidenced integration of the gels within the host tissue with no persistent inflammatory response. The DMA showed that the gels maintained their mechanical stability, and weight measurements by the end of the experiments reinforced these observations. Taking together all these data, it can be concluded that gellan gum hydrogels are adequate for injectable applications and in situ cell delivery in cartilage regeneration approaches. This new biomaterial has generated interesting and promising results that justify its use in further in vivo studies highly benefiting from their ease of processing performed under nonharmful conditions to the cells with the ability to be injected at the defect site in a minimally invasive manner. Its ability to be used as an injectable system using the described processing methodologies and the preliminary in vivo response performed by the subcutaneous implantation in mice are the two major innovations presented in this work.

\section{Acknowledgments}

J.T. Oliveira would like to acknowledge the Portuguese Foundation for Science and Technology for his grant (SFRH/BD17135/2004). The authors would like to thank the patients at Hospital de S. Marcos, Braga, Portugal for the donation of the biological samples, and the medical staff for their help and support. The authors would also like to thank the Institute for Health and Life Sciences, University of Minho, Braga, Portugal, for allowing the use of their research facilities. This work was carried out under the scope of the European NoE EXPERTISSUES (NMP3-CT-2004500283) and partially supported by the European Project HIPPOCRATES (STRP 505758-1).

\section{Disclosure Statement}

No competing financial interests exist.

\section{References}

1. Hunt, S.A., Jazrawi, L.M., and Sherman, O.H. Arthroscopic management of osteoarthritis of the knee. J Am Acad Orthop Surg 10, 356, 2002.

2. Caplan, A.I., Elyaderani, M., Mochizuki, Y., Wakitani, S., and Goldberg, V.M. Principles of cartilage repair and regeneration. Clin Orthop Relat Res 342, 254, 1997.

3. Cancedda, R., Dozin, B., Giannoni, P., and Quarto, R. Tissue engineering and cell therapy of cartilage and bone. Matrix Biol 22, 81, 2003.

4. Ge, Z., Hu, Y., Heng, B.C., Yang, Z., Ouyang, H., Lee, E.H., and Cao, T. Osteoarthritis and therapy. Arthritis Rheum 55, 493, 2006.

5. Mano, J.F., and Reis, R.L. Osteochondral defects: present situation and tissue engineering approaches. J Tissue Eng Regen Med 1, 261, 2007. 
6. Brittberg, M., Lindahl, A., Nilsson, A., Ohlsson, C., Isaksson, O., and Peterson, L. Treatment of deep cartilage defects in the knee with autologous chondrocyte transplantation. $\mathrm{N}$ Engl J Med 331, 889, 1994.

7. Risbud, M.V., and Sittinger, M. Tissue engineering: advances in in vitro cartilage generation. Trends Biotechnol 20, 351, 2002.

8. Tuzlakoglu, K., Alves, C.M., Mano, J.F., and Reis, R.L. Production and characterization of chitosan fibers and 3-D fiber mesh scaffolds for tissue engineering applications. Macromol Biosci 4, 811, 2004.

9. Lee, C.R., Breinan, H.A., Nehrer, S., and Spector, M. Articular cartilage chondrocytes in type I and type II collagenGAG matrices exhibit contractile behavior in vitro. Tissue Eng 6, 555, 2000.

10. Hutmacher, D.W. Scaffolds in tissue engineering bone and cartilage. Biomaterials 21, 2529, 2000.

11. Stile, R.A., Burghardt, W.R., and Healy, K.E. Synthesis and characterization of injectable poly( $\mathrm{N}$-isopropylacrylamide)based hydrogels that support tissue formation in vitro. Macromolecules 32, 7370, 1999.

12. Elisseeff, J., McIntosh, W., Anseth, K., Riley, S., Ragan, P., and Langer, R. Photoencapsulation of chondrocytes in poly(ethylene oxide)-based semi-interpenetrating networks. J Biomed Mater Res 51, 164, 2000.

13. Drury, J.L., and Mooney, D.J. Hydrogels for tissue engineering: scaffold design variables and applications. Biomaterials 24, 4337, 2003.

14. Hoemann, C.D., Sun, J., Légaré, A., McKee, M.D., and Buschmann, M.D. Tissue engineering of cartilage using an injectable and adhesive chitosan-based cell-delivery vehicle. Osteoarthritis Cartilage 13, 318, 2005.

15. Schagemann, J.C., Erggelet, C., Chung, H.W., Lahm, A., Kurz, H., and Mrosek, E.H. Cell-laden and cell-free biopolymer hydrogel for the treatment of osteochondral defects in a sheep model. Tissue Eng Part A 15, 75, 2009.

16. Smith, A.M., Shelton, R.M., Perrie, Y., and Harris, J.J. An initial evaluation of gellan gum as a material for tissue engineering applications. J Biomater Appl 22, 241, 2007.

17. Oliveira, J.T., Picciochi, R., Santos, T.C., Martins, L., Pinto, L.G., Malafaya, P.B., Sousa, R.A., Marques, A.P., Castro, A.G., Mano, J.F., Neves, N.M., and Reis, R.L. Injectable gellan gum hydrogels as supports for cartilage tissue engineering applications. Annual Tissue Engineering and Regenerative Medicine International Society-European Chapter Meeting, Mary Ann Liebert Inc., Porto, Portugal, 2008, p. OP165.

18. Gong, Y., Wang, C., Lai, R.C., Su, K., Zhang, F., and Wang, D.-a. An improved injectable polysaccharide hydrogel: modified gellan gum for long-term cartilage regeneration in vitro. J Mater Chem 19, 1968, 2009.

19. Jansson, P.-E., Lindberg, B., and Sandford, P.A. Structural studies of gellan gum, an extracellular polysaccharide elaborated by Pseudomonas elodea. Carbohydr Res 124, 135, 1983.

20. Moorhouse, R., Colegrove, G.T., Sandford, P.A., Baird, J.K., and Kang, K.S. PS-60: A New Gel-Forming Polysaccharide. Washington, DC: D.A. Brandt, 1981.

21. Rozier, A., Mazuel, C., Grove, J., and Plazonnet, B. Gelrite(R): a novel, ion-activated, in-situ gelling polymer for ophthalmic vehicles. Effect on bioavailability of timolol. Int J Pharm 57, 163, 1989.

22. Grasdalen, H., and Smidsrod, O. Gelation of gellan gum. Carbohydr Polym 7, 371, 1987.
23. Kang, K.S., and Veeder, G.T. Polysaccharide S-60 and bacterial fermentation process for its preparation. United States Patent 4326053 (1982).

24. Ogawa, E., Takahashi, R., Yajima, H., and Nishinari, K. Effects of molar mass on the coil to helix transition of sodiumtype gellan gums in aqueous solutions. Food Hydrocoll 20, 378,2006

25. Oliveira, J.T., Martins, L., Picciochi, R., Malafaya, P.B., Sousa, R.A., Neves, N.M., Mano, J.F., and Reis, R.L. Gellan gum: a new biomaterial for cartilage tissue engineering applications, J Biomed Mater Res A, Aug 5, 2009 (Epub ahead of print).

26. Quinn, F.X., Hatakeyama, T., Yoshida, H., Takahashi, M., and Hatakeyama, H. The conformational properties of gellan gum hydrogels. Polym Gels Netw 1, 93, 1993.

27. Ogawa, E., Matsuzawa, H., and Iwahashi, M. Conformational transition of gellan gum of sodium, lithium, and potassium types in aqueous solutions. Food Hydrocoll 16, 1, 2002.

28. Miyoshi, E., Takaya, T., and Nishinari, K. Rheological and thermal studies of gel-sol transition in gellan gum aqueous solutions. Carbohydr Polym 30, 109, 1996.

29. Mao, R., Tang, J., and Swanson, B.G. Texture properties of high and low acyl mixed gellan gels. Carbohydr Polym 41, 331, 2000.

30. Coviello, T., Dentini, M., Rambone, G., Desideri, P., Carafa, M., Murtas, E., Riccieri, F.M., and Alhaique, F. A novel cocrosslinked polysaccharide: studies for a controlled delivery matrix. J Control Release 55, 57, 1998.

31. Kubo, W., Miyazaki, S., and Attwood, D. Oral sustained delivery of paracetamol from in situ-gelling gellan and sodium alginate formulations. Int J Pharm 258, 55, 2003.

32. Sanzgiri, Y.D., Maschi, S., Crescenzi, V., Callegaro, L., Topp, E.M., and Stella, V.J. Gellan-based systems for ophthalmic sustained delivery of methylprednisolone. J. Control Release 26, 195, 1993.

33. Crawford, A., and Dickinson, S.C. Chondrocyte isolation, expansion, and culture on polymer scaffolds, In: Hollander, A.P., and Hatton, P.V., eds. Methods in molecular biology: Biopolymer methods in tissue engineering. Totowa, NJ: Humana Press Inc., 238, 147, 2004.

34. Livak, K.J., and Schmittgen, T.D. Analysis of relative gene expression data using real-time quantitative PCR and the $2^{-\Delta \Delta}$ CT method. Methods 25, 402, 2001.

35. Page, D.C., and Lander, E.S. Available at http://frodo .wi.mit.edu/. 2008.

36. Froimson, M.I., Ratcliffe, A., Gardner, T.R., and Mow, V.C. Differences in patellofemoral joint cartilage material properties and their significance to the etiology of cartilage surface fibrillation. Osteoarthritis Cartilage 5, 377, 1997.

37. Nettles, D.L., Vail, T.P., Morgan, M.T., Grinstaff, M.W., and Setton, L.A. Photocrosslinkable hyaluronan as a scaffold for articular cartilage repair. Ann Biomed Eng 32, 391, 2004.

38. Hoffman, A.S. Hydrogels for biomedical applications. Adv Drug Deliv Rev 54, 3, 2002.

39. Dickstein, K., Hapnes, R., and Aarsland, T. Comparison of aqueous and gellan ophthalmic timolol with placebo on the 24-hour heart rate response in patients on treatment for glaucoma. Am J Ophthalmol 132, 626, 2001.

40. Weber, M., Steinert, A., Jork, A., Dimmler, A., Thürmer, F., Schütze, N., Hendrich, C., and Zimmermann, U. Formation of cartilage matrix proteins by BMP-transfected murine mesenchymal stem cells encapsulated in a novel class of alginates. Biomaterials 23, 2003, 2002. 
41. Knudson, C.B., and Knudson, W. Cartilage proteoglycans. Semin Cell Dev Biol 12, 69, 2001.

42. Aigner, T., Gebhard, P.M., Schmid, E., Bau, B., Harley, V., and Pöschl, E. SOX9 expression does not correlate with type II collagen expression in adult articular chondrocytes. Matrix Biol 22, 363, 2003.

43. Tew, S.R., Clegg, P.D., Brew, C.J., Redmond, C.M., and Hardingham, T.E. SOX9 transduction of a human chondrocytic cell line identifies novel genes regulated in primary human chondrocytes and in osteoarthritis. Arthritis Res Ther 9, R107, 2007.

44. Lefebvre, V., Li, P., and de Crombrugghe, B. A new long form of Sox5 (L-Sox5), Sox6 and Sox9 are coexpressed in chondrogenesis and cooperatively activate the type II collagen gene. Embo J 17, 5718, 1998.

45. Akiyama, H., Chaboissier, M.C., Martin, J.F., Schedl, A., and de Crombrugghe, B. The transcription factor Sox9 has essential roles in successive steps of the chondrocyte differentiation pathway and is required for expression of Sox 5 and Sox6. Genes Dev 16, 2813, 2002.
Address correspondence to: João T. Oliveira, Ph.D.

3B's Research Group-Biomaterials, Biodegradables and Biomimetics

Department of Polymer Engineering Headquarters of the European Institute of Excellence on Tissue Engineering and Regenerative Medicine University of Minho AvePark

Zona Industrial da Gandra S. Cláudio do Barco 4806-909 Caldas das Taipas Guimarães Portugal

E-mail: joao.oliveira@dep.uminho.pt

Received: February 19, 2009

Accepted: August 24, 2009

Online Publication Date: October 7, 2009 


\section{This article has been cited by:}

1. Shiva H. Jahromi, Liam M. Grover, Jennifer Z. Paxton, Alan M. Smith. 2011. Degradation of polysaccharide hydrogels seeded with bone marrow stromal cells. Journal of the Mechanical Bebavior of Biomedical Materials . [CrossRef]

2. Haeyeon Lee, Stephanie Fisher, Michael S. Kallos, Christopher J. Hunter. 2011. Optimizing gelling parameters of gellan gum for fibrocartilage tissue engineering. Journal of Biomedical Materials Research Part B: Applied Biomaterials n/a-n/a. [CrossRef]

3. Daniela F. Coutinho, Shilpa V. Sant, Hyeongho Shin, João T. Oliveira, Manuela E. Gomes, Nuno M. Neves, Ali Khademhosseini, Rui L. Reis. 2010. Modified Gellan Gum hydrogels with tunable physical and mechanical properties. Biomaterials 31:29, 7494-7502. [CrossRef]

4. João T. Oliveira, Leandro S. Gardel, Tommaso Rada, Luís Martins, Manuela E. Gomes, Rui L. Reis. 2010. Injectable gellan gum hydrogels with autologous cells for the treatment of rabbit articular cartilage defects. Journal of Orthopaedic Research 28:9, 1193-1199. [CrossRef]

5. J. T. Oliveira, R. L. Reis. 2010. Polysaccharide-based materials for cartilage tissue engineering applications. Journal of Tissue Engineering and Regenerative Medicine n/a-n/a. [CrossRef]

6. J. Silva-Correia, J. M. Oliveira, S. G. Caridade, J. T. Oliveira, R. A. Sousa, J. F. Mano, R. L. Reis. 2010. Gellan gum-based hydrogels for intervertebral disc tissue-engineering applications. Journal of Tissue Engineering and Regenerative Medicine n/a-n/a. [CrossRef] 